\title{
Extracorporeal shock wave lithotripsy allows successful endoscopic removal of a fractured stone basket trapped in the pancreatic duct
}

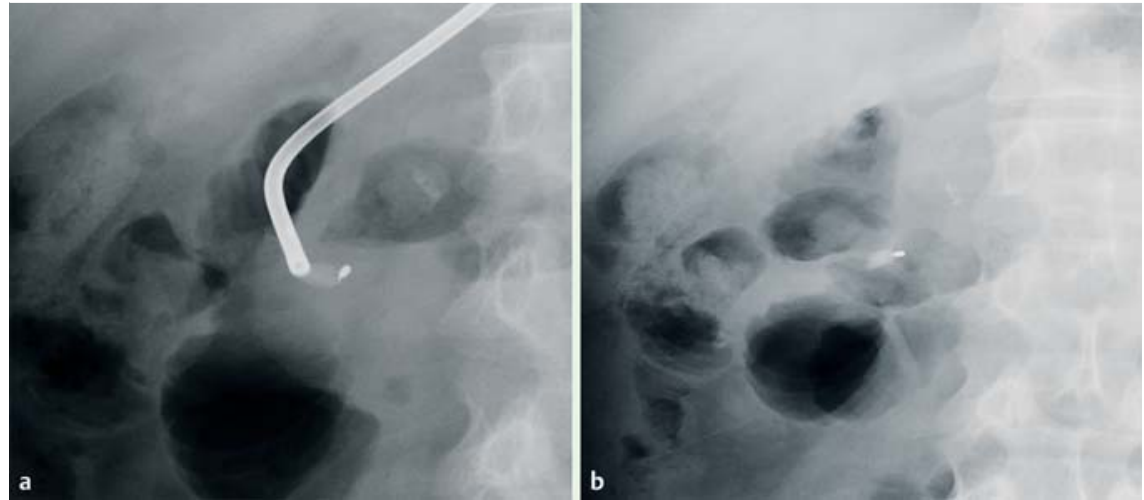

Fig. 1 Radiographic images showing: a a captured 9-mm pancreaticolith with mechanical lithotripsy being performed during endoscopic retrograde pancreatography (ERCP); $\mathbf{b}$ the fractured basket that was trapped in the pancreatic duct with the pancreaticolith.

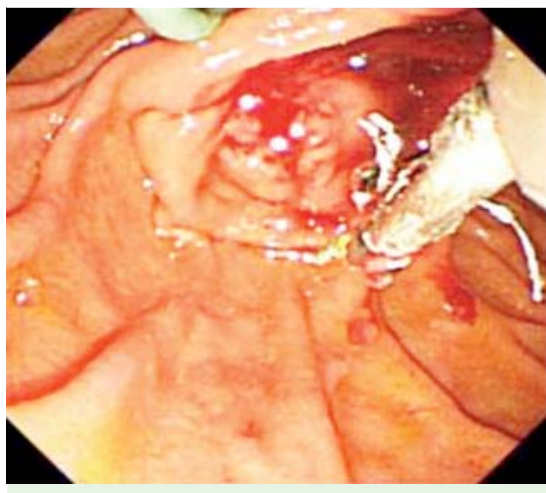

Fig. 3 Endoscopic view showing the fractured basket being captured by the forceps and extracted from the major papilla.

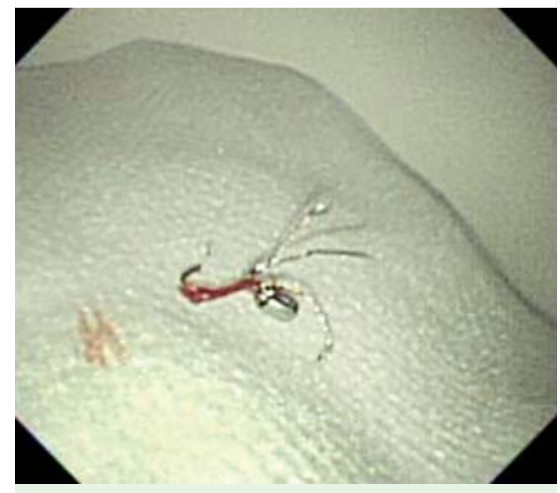

Fig. 4 Photograph showing the fractured basket, which was completely removed.

became tangled up in the fractured basket ( Fig. 1 b). Attempted removal of the fractured basket and pancreaticolith complex failed because they were tightly impacted in the narrow portion of the MPD. To minimize the risk of pancreatitis due to obstruction of the MPD, a 5-Fr plastic stent was inserted through the minor duodenal papilla.

Extracorporeal shock wave lithotripsy (ESWL) to the impacted pancreaticolith was started on the day after the ERCP using a third-generation lithotriptor (PiezoLith 3000 plus; ELvation Medical $\mathrm{GmbH}$, Germany) [1]. The repeated ESWL could be focused accurately on the pancreaticolith because it was held tightly together with the fractured basket in the pancreatic duct. After the 11th ESWL

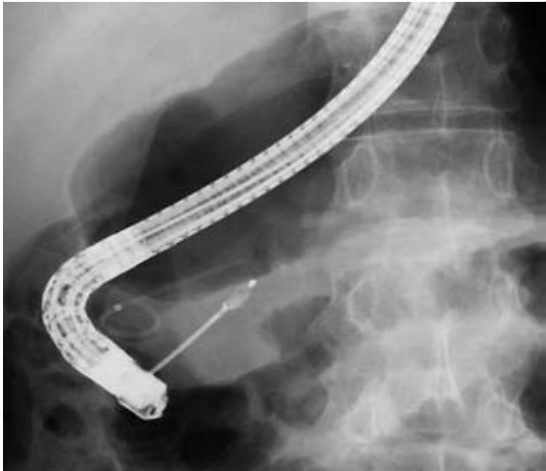

Fig. 2 Radiographic image during repeat endoscopic retrograde cholangiopancreatography (ERCP) after 11 sessions of extracorporeal shockwave lithotripsy (ESWL) showing a forceps reaching the fractured basket to extract it.

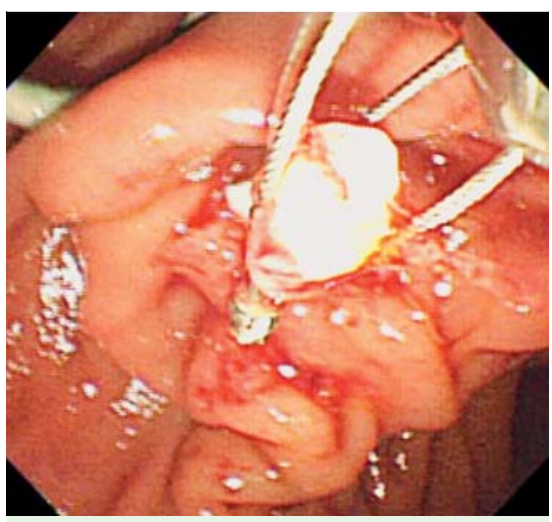

Fig.5 Endoscopic view showing the impacted pancreaticolith being removed in a basket.

treatment (3000 shocks per session at an intensity of 16 on a scale of $1-20$ ), a further ERCP was attempted.

A guidewire was successfully passed through the impacted basket and stone. After a 6-mm balloon (Hurricane Rx hydrostatic balloon; Boston Scientific, Natick Massachusetts, USA) had been dilated in the narrow portion of the MPD, the fractured basket was removed with a forceps (FB-19N-1; Olympus, Tokyo, Japan) ( $\bullet$ Figs. 2-4). Following this, the fragmented pancreaticolith was also successfully removed by sweeping with the basket and balloon ( $\bullet$ Fig. 5).

Endoscopy_UCTN_Code_CPL_1AK_2AH

Competing interests: None 
Min Keun Cho, Tae Jun Song, Do Hyun Park, Sang Soo Lee, Dong Wan Seo, Sung Koo Lee, Myung-Hwan Kim

Department of Internal Medicine, University of Ulsan College of Medicine, Asan Medical Center, Seoul, Republic of Korea

\section{Reference}

1 Thomas M, Howell DA, Carr-Locke D et al. Mechanical lithotripsy of pancreatic and biliary stones: complications and available treatment options collected from expert centers. Am J Gastroenterol 2007; 102: $1896-1902$

\section{Bibliography}

Dol http://dx.doi.org/

10.1055/s-0042-101410

Endoscopy 2016; 48: E65-E66

(c) Georg Thieme Verlag KG

Stuttgart · New York

ISSN 0013-726X
Corresponding author

\section{Tae Jun Song}

Department of Internal Medicine,

University of Ulsan College of Medicine

Asan Medical Center

88, Olympic-Ro 43-Gil

Songpa-gu

Seoul 05505

South Korea

Fax: +82-2-4760824

medi01@naver.com 